RESEARCH PAPER

\title{
Tobacco attributable deaths in South Africa
}

\author{
F Sitas, M Urban, D Bradshaw, D Kielkowski, S Bah, R Peto
}

Tobacco Control 2004;13:396-399. doi: 10.1136/tc.2004.007682

See end of article for authors' affiliations .....................

Correspondence to: A Professor Freddy Sitas, the Cancer Council New South Wales, P.O. Box 572, Kings Cross, NSW, 2011, Australia. Email: freddys@nswcc.org.au

Received 10February 2004 Accepted 4 June 2004

\begin{abstract}
Background: In mid 1998, a question "Was the deceased a smoker five years ago?" was introduced on the newly revised South African death notification form.

Design: A total of 16230 new death notification forms from 1998 have been coded, and comparison of the prevalence of smoking among those who died of different causes was used to estimate, by case-control comparisons, tobacco attributed mortality in South Africa. Cases comprised deaths from causes known (from other studies) to be causally associated with smoking, and controls comprised deaths from medical conditions expected to be unrelated to smoking. Those who died from external causes, and from diseases strongly related to alcohol consumption, were excluded.

Subjects: Reports were available from 5340 deceased adults (age 25+), whose smoking status was given by a family member.

Results: Significantly increased risks were found for deaths from tuberculosis (odds ratio (OR) 1.61, 95\% confidence interval (CI) 1.23 to 2.11 ), chronic obstructive pulmonary disease (COPD) (OR 2.5, 95\% Cl 1.9 to 3.4 ), lung cancer (OR $4.8,95 \% \mathrm{Cl} 2.9$ to 8.0 ), other upper aerodigestive cancer (OR $3.0,95 \% \mathrm{Cl} 1.9$ to 4.9 ) and ischaemic heart disease (OR $1.7,95 \% \mathrm{Cl} 1.2$ to 2.3 ).

Conclusion: If smokers had the same death rate as non-smokers, $58 \%$ of lung cancer deaths, $37 \%$ of COPD deaths, $20 \%$ of tuberculosis deaths, and $23 \%$ of vascular deaths would have been avoided. About $8 \%$ of all adult deaths in South Africa (more than 20000 deaths a year) were caused by smoking.
\end{abstract}

$\mathrm{S}$ outh Africa is a middle-income country of approximately 45 million people. The population is heterogeneous and using the population groups defined by the most recent census (2001) shows that about $77 \%$ are of African origin, $10 \%$ are whites of European origin, $9 \%$ are coloured (of mixed origin), and $2.5 \%$ are Asian, most of whom are of Indian descent. ${ }^{1}$

In 1992 it was found that a third of the adults ( $\geqslant 18$ years) in South Africa were smokers (52\% male, $17 \%$ female). ${ }^{2}$ Smoking was prevalent among men of all population groups (53\% in African, $43 \%$ in white, $58 \%$ in coloured, and $48 \%$ in Asian/Indian), and it is noteworthy that smoking rates among Africans exceeded those of whites. Only 10\% of African women were smokers compared with $27 \%$ of white and $59 \%$ of coloured women. Average annual consumption of manufactured cigarettes per adult ( 15 years and older) rose from 1340 in $1970-72$ to 1720 in $1990-92 .^{3}$ From about 200 billion cigarettes consumed in 1991, consumption declined to 70 billion in $2001 .^{4}$

Methods of estimating tobacco attributed mortality that are appropriate for Western developed countries may not be applicable elsewhere. ${ }^{5}$ One way to estimate tobacco attributed mortality in developing populations is to study retrospectively a large number of people who have recently died, ascertaining their previous smoking habits by interviewing the family, and recording the underlying disease that caused death. This has been done in China ${ }^{67}$ and India ${ }^{8}$ where the next of kin of the deceased individuals were visited by research teams and answered questions about their own smoking status and about the smoking status of their deceased relative. Comparisons of smoking could then be made either between people who had died of different diseases (as in the present report) or between those who had died and those who had not (using the surviving relatives as unmatched controls).

In South Africa death registration is compulsory. A new death notification form was introduced in 1998 in an extensive effort by the South African government to improve coverage and to conform to international standards regarding both medical and non-medical cause of death notification. ${ }^{9}$ The incorporation of former black homelands into a unitary state has now increased the proportion of adult deaths that are certified to over $90 \% .{ }^{10}$ The new death notification form (and, for the first time, an instruction manual on how to complete it $^{11}$ ) was introduced in June 1998. The cause of death details are recorded using the World Health Organization recommended format (International classification of diseases, 10th revision (ICD-10)) to enable identification of the underlying cause. Further demographic details about the deceased are also included-for example, level of education, population group, and usual residence. In addition, the question "Was the deceased a smoker five years ago? (Yes/ No/Not applicable/Minor)" has been introduced to provide a direct estimate of tobacco attributed mortality ${ }^{12}$ using a national death notification system.

\section{METHODS}

The South African death notification system was used to gather this information. A doctor or nurse ascertained whether a death was natural or suspicious and filled the medical section of the death notification form accordingly. Forms are passed on to the local Department of Home Affairs who check the identity of the deceased and of the next of kin. Deaths that may be due to an external cause are dealt with by a pathologist, who may perform a necropsy, before releasing the body for burial. Once such investigations are complete, the Department of Home Affairs issues a burial order and a death certificate to the next-of-kin. These notification forms are centrally microfiched and the paper original sent to Statistics South Africa for coding and statistical reporting.

As data processing by the Vital Statistics Section of Statistics South Africa has a lag of a minimum of about five years, a sample of 16230 new forms (approximately 5\%) was gathered by asking all local Department of Home Affairs offices to submit copies to Statistics South Africa of the first 200 death notifications, starting three months after implementation (that is, from October 1998) to a cut-off of 
December 1998. Trained nosologists, from the Vital Statistics section of Statistics South Africa, coded the underlying cause of death using the medical information on the new notification form which is more detailed than previously; thereafter the whole form was captured on computer.

A case-control analysis was used to estimate tobacco attributed mortality. "Cases" comprised deaths from diseases known from studies elsewhere to be potentially related to smoking, and "controls" comprised deaths from other defined medical conditions expected to be largely unrelated to smoking. Specifically, cases comprised adults (age 25+) with death attributable to tuberculosis, other lung infection, chronic obstructive pulmonary disease (COPD), lung cancer, and cancers of the nose, oral cavity, larynx, pharynx, oesophagus, stomach, liver, bile duct, pancreas, bladder, kidney, and cervix uteri (all combined into two categories due to small sample sizes), ischaemic heart disease, and stroke and other vascular disease (excluding rheumatic heart disease).

The controls comprised adults with deaths caused by other infectious diseases (A00-A09, A20-B99, $\mathrm{n}=410$ ); benign neoplasms (D00-D89, $\mathrm{n}=103$ ); endocrine diseases (E00E89, $n=264)$; diseases of the nervous system (G00-G99, $\mathrm{n}=81$ ); female breast and genital cancers (other than cervix) (C50-C52, C54-C58, $\mathrm{n}=52$ ); male genital cancers (C60-C63, $\mathrm{n}=33)$; colorectal cancer $(\mathrm{C} 18-\mathrm{C} 21, \mathrm{n}=32)$; cancers of the bone, skin, connective and soft tissue (C40C49, $\mathrm{n}=22$ ); haematological cancers (C81-C96, $\mathrm{n}=20$ ); diseases of the genitourinary system $(\mathrm{N} 00-\mathrm{N} 99, \mathrm{n}=81)$, diseases of the digestive system excluding varices (K35-K66, $\mathrm{n}=40$ ); obstetric conditions (O00-O99, $\mathrm{n}=12$ ); musculoskeletal conditions (M00-M99, $\mathrm{n}=8$ ); cancers of the eye, central nervous system, $(\mathrm{C} 69 ; \mathrm{n}=1)$; endocrine glands (C69-C75, $\mathrm{n}=2$ ); congenital malformations (Q00-Q93, $\mathrm{n}=2$ ); eye disorders (H00-H99, $\mathrm{n}=2$ ), and diseases of the skin (L00-L99, $\mathrm{n}=2$ ).

We excluded from the case-control comparison persons with ill defined causes of death (as we did not know whether they should be cases or controls), persons dying from diseases strongly associated with alcohol (cirrhosis, pancreatitis, peptic ulcer, and oesophageal varices) and persons dying from external causes, who, from other studies, $^{13}$ were expected to include a non-causal excess of smokers.

Data were analysed using unmatched unconditional logistic regression to estimate odds ratios (OR), standardised for age (25-34, 35-44, 45-54, 55-64, 65-74, and 75+ years), education (none, primary (up to seven years)), secondary or

\begin{tabular}{|c|c|c|}
\hline Characteristic & $\begin{array}{l}\text { Cases } \\
n=4295\end{array}$ & $\begin{array}{l}\text { Controls } \\
n=1952\end{array}$ \\
\hline Age group (years) & (\%) & (\%) \\
\hline $25-34$ & 45.7 & 47.7 \\
\hline $35-44$ & 49.5 & 44.0 \\
\hline $45-54$ & 43.1 & 42.9 \\
\hline $55-64$ & 40.7 & 38.6 \\
\hline $65-74$ & 36.6 & 40.2 \\
\hline $75+$ & 35.5 & 38.2 \\
\hline \multicolumn{3}{|l|}{ Education } \\
\hline None & 19.4 & 18.5 \\
\hline Primary & 19.4 & 19.0 \\
\hline Secondary/tertiary & 16.6 & 13.1 \\
\hline Unknown & 66.2 & 70.1 \\
\hline \multicolumn{3}{|c|}{ Relationship of informant to deceased } \\
\hline Parent & 42.8 & 54.4 \\
\hline Spouse & 38.4 & 40.6 \\
\hline Son/daughter & 36.7 & 41.2 \\
\hline Other relative & 44.9 & 42.5 \\
\hline
\end{tabular}

tertiary, and unknown), population group (black, white, Asian, coloured, unknown), and by sex, where appropriate. Attributable risks and fractions were estimated in the usual way as $\mathrm{P} \times(\mathrm{OR}-1) /(\mathrm{P} \times \mathrm{OR})+(1-\mathrm{P})$, where $\mathrm{P}$ is the prevalence of smokers in the control group. ${ }^{14}$ This study was approved by the University of Witwatersrand human research ethics committee (medical).

Of the 16230 death notifications included, almost all of which recorded sex and age, 12959 were from persons of a known sex and over 25 years of age. Of this group 9085 death notification forms had informants who were a close family member (son, daughter, parent, or spouse). This analysis is based on the data from these 2946 men and 2394 women with close family informants who had smoking status reported.

After standardisation for age, sex, education, ethnicity, and disease, there was no significant difference in the response rate for the question on the smoking status of the deceased reported by different family members $\left(\chi^{2}=5.08,3 \mathrm{df}\right.$, $\mathrm{p}=0.166)$. Likewise, the education level of the informant $\left(\chi^{2}=6.6,3 \mathrm{df}, \mathrm{p}=0.086\right)$, and the age group of the informant $\left(\chi^{2}=5.38,5 \mathrm{df}, \mathrm{p}=0.372\right)$, did not affect the responses on smoking, giving some assurance that relatives of those with tobacco related diseases were not likely to differentially report the smoking status of their deceased relatives (table 1). Further quality control indices of the new death notification form have been published elsewhere. ${ }^{15}$

\section{RESULTS}

The prevalence of smoking in the controls was $54.9 \%$ in males $(298 / 543)$ and $15.8 \%$ in females (92/581). This is similar to prevalence rates found in other national population based surveys conducted in 1995 (52\% male, 17\% female). ${ }^{2}$

Significantly increased risks (OR) were found for deaths from causes already known, or thought to be associated with tobacco (table 2). These are tuberculosis (OR 1.61, 95\% confidence interval (CI) 1.23 to 2.11 ), COPD (OR 2.53, 95\% CI 1.90 to 3.38 ), lung cancer (OR $4.79,95 \%$ CI 2.86 to 8.01 ), upper aerodigestive cancer (OR 3.04, 95\% CI 1.89 to 4.89 ), and ischaemic heart disease (OR 1.69, 95\% CI 1.24 to 2.33 ). Significant excesses of smokers' increases in risk were also found for causes of death previously thought to be confounded by smoking, these being cirrhosis of the liver and other alcohol related conditions (OR 1.58, 95\% CI 1.11 to 2.28 ), and external causes (OR 1.37, 95\% CI 1.09 to 1.73 ).

\section{DISCUSSION}

The relative risk of death from lung cancer in smokers are lower than those found in two other South African casecontrol studies among Africans only (OR 10.7 and 5.5 for male and female smokers ${ }^{16}$ in a mainly rural setting of the Northern province, and 9.8 in males and 13.5 in females in Johannesburg/Soweto ${ }^{17}$ ). This may be partly because metastases to the lung from other anatomic sites may be miscertified as lung cancer in routine death records; partly because in the present study some recent or ex-smokers may have been reported as non-smokers; partly because some of the controls may in fact have been killed by tobacco; partly due to occupational factors; but chiefly because those who now smoke may not have smoked intensively for long enough to suffer the full risks of persistent cigarette use. Nevertheless, even with all these limitations and sources of dilution (which would also apply to other causes of death), at least $60 \%$ of lung cancers would be attributed to tobacco.

Ischaemic heart disease comprised about a third of all vascular deaths and the effect of tobacco on vascular disease appears, at this stage of the epidemic, to be lower than that expected from western countries. Nevertheless $20 \%$ of all 


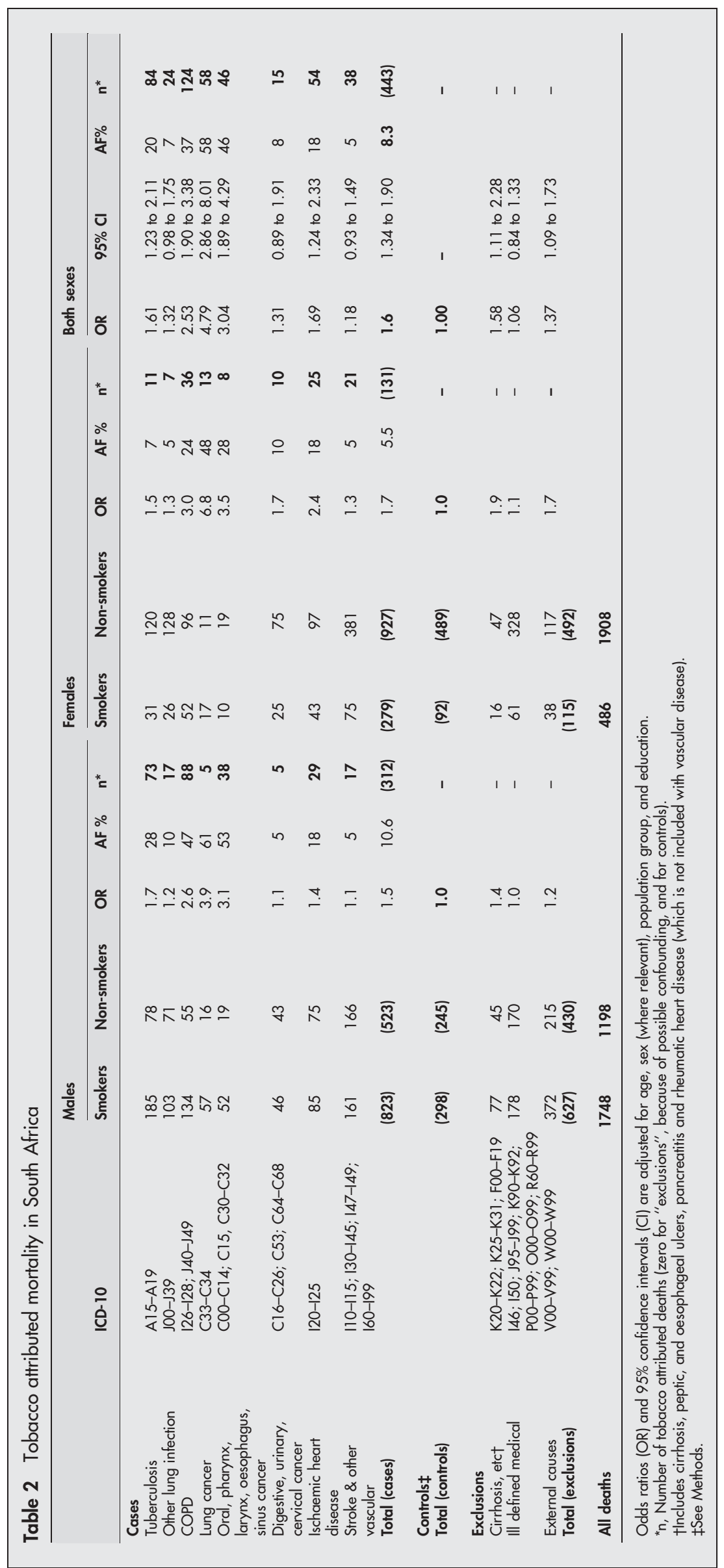




\section{What this paper adds}

We believe this study describes the first attempt to include a question on smoking on a revised official death notification form for routine monitoring of the evolution of the tobacco epidemic. Using a case-control methodology, we were able to demonstrate that the results are reliable, and concordant to what may be expected from indirect calculations of the burden of tobacco related disease. Data on the effect of tobacco are largely lacking in Africa. This initiative may provide useful and, up to a point, generalisable data for the continent. We also hope that by publishing this paper, other countries (even those with limited death registration systems) may consider altering their death notification system to incorporate useful questions on smoking.

vascular deaths would be attributed to smoking, if the observed excess were causal.

South Africa has a high incidence of tuberculosis and this rate has been increasing dramatically as a result of the HIV epidemic. ${ }^{10}$ Notably, about $20 \%$ of deaths caused by tuberculosis would be avoided if smokers had the same death rates as non-smokers. Studies in China, ${ }^{67}$ India, $^{8}$ and the $\mathrm{UK}^{13}$ have also found smokers to have higher age standardised death rates from tuberculosis than non-smokers. Given the high local prevalence of latent tuberculosis and the ability of smoking to damage the lung, this excess may well be largely or wholly causal, making smoking a cause of one out of five deaths from tuberculosis. This finding may be particularly relevant to the mixed race (coloured) population of South Africa where smoking rates are 58\% in males and 59\% in females $^{2}$ and tuberculosis rates in this population are unusually high.

Latent tuberculous infection can be activated by HIV and some may hypothesise that, as in some western countries, persons infected with HIV smoke more than uninfected individuals. However, in a study of 2910 black cancer and vascular disease patients mainly from Johannesburg and Soweto, South Africa (Sitas et al, unpublished data), the age adjusted prevalence of HIV was 5.3\% in non-smokers, $6.6 \%$ in ex-smokers, and $5.7 \%$ in current smokers $(p=0.4)$, so at least, in an urban South African setting, smoking does not seem to be associated with lifestyles leading to an increased risk of HIV.

More smoking attributed deaths would involve COPD $(\mathrm{n}=124)$, tuberculosis $(\mathrm{n}=87)$, and vascular disease $(\mathrm{n}=92)$ than lung cancer $(\mathrm{n}=57)$. If the smoking associated proportions in table 2 are typical of South Africa as a whole, then in 1998 about 8\% of adult deaths (21 500 deaths per year) in South Africa could be attributed to smoking. These estimates are quite close to those derived for South Africa from indirect methods. ${ }^{316}$ Similar proportions of adult deaths attributed to tobacco have been found-for example, in China $(13 \%)^{6}$ and Mexico $(15 \%)^{18}$-but these proportions are likely to increase. In countries like the USA and UK about $25 \%$ of deaths are attributed to smoking. ${ }^{3} 19$

The advantage of this simple methodology is that once further data are accumulated, better estimates can be derived by subgroups like population group, and by province, and as the system settles down it will help monitor the national and local trends in this epidemic, whose effects in Africa or other countries have been little studied. More countries should consider including questions about the smoking status of the deceased on their death notification forms, allowing comparisons between places with different tobacco control strategies.

\section{Authors' affiliations}

F Sitas, M Urban, National Health Laboratory Service, and

Witwatersrand University, South Africa

D Bradshaw, Burden of Disease Research Unit, Medical Research Council of South Africa

D Kielkowski, National Centre for Occupational Health, National Health Laboratory Service and Witwatersrand University

S Bah, Statistics South Africa

R Peto, Clinical Trial Service Unit, University of Oxford, Oxford, UK

Supported by: South African Medical Research Council, Cancer Association of South Africa, National Health Laboratory Service, University of the Witwatersrand, Swiss-RE Southern Africa, Health Systems Trust, University of Oxford Clinical Trial Service Unit (CTSU), Yvonne Klugman Memorial Fund and National Health Information System, Department of Health; and assisted by S Khotu, M Cassim, A Mogkabudi, E Kritzinger, Y Saloojee, N Mavimbela, D Yach, AD Lopez, $R$ Pacella-Norman and J Boreham.

Conflict of interest: None.

\section{REFERENCES}

1 Statistics South Africa. Census 2001: Census in brief. Pretoria: Statistics South Africa, 2003, www.statssa.gov.za [Accessed 8 July 2003].

2 Reddy P, Meyer-Weitz A, Yach D. Smoking status, knowledge of health effects and attitudes towards tobacco control in South Africa. South African Med J 1996;86:1389-93.

3 World Health Organization. Tobacco or health: a global status report. Geneva: WHO, 1997

4 (South African) National Council Against Smoking. South African Cigarette Tax vs Consumption. www.againstsmoking.org [Accessed 18 May 2004].

5 Peto R, Lopez A, Boreham J, et al. Mortality from smoking in developed countries 1950-2000. Oxford: ICRF/WHO, Oxford University Press, 1994.

6 Liu B-Q, Peto R, Chen Z-M, et al. Emerging tobacco hazards in China: 1. Retrospective proportional mortality study of one million deaths. $B M J$ 1998;317:1411-22

7 Lam TH, Ho SY, Hedley AJ, et al. Mortality and smoking in Hong Kong: casecontrol study of all adult deaths in 1998. BMJ 2001;323:361-2.

8 Gajalakshmi V, Peto R, Kanaka TS, et al. Smoking and mortality from tuberculosis and other diseases in India. Retrospective study of 43000 adult male deaths and 35000 controls. Lancet 2003;362:507-15.

9 Bradshaw D, Kielkowski D, Sitas F. New birth and death registration forms-a foundation for the future, a challenge to health workers? South African Med J 1998;88:971-4.

10 Dorrington R, Bourne D, Bradshaw D, et al. The impact of HIV/Aids on adult mortality. MRC Technical Report. MRC: Cape Town, 2001. ISBN: 1-91980914-7. www.mrc.ac.za/bod/bod.htm [Accessed 18 July 2003]

11 Republic of South Africa. Department of Health. National Health Information System. Training Manual for the Death Notification Form (BI 1663). Pretoria, 1999. http://www.doh.gov.za/nhis/index.html [Accessed 6 Nov 2003].

12 Sitas F, Pacella-Norman R, Peto R, et al. Why do we need a large study on tobacco-attributed mortality in South Africa? South African Med J 1998:88:925-6.

13 Doll R, Peto R, Wheatley K, et al. Mortality in relation to smoking: 40 years' observations on British male doctors. BMJ 1994;309:901-1 1.

14 Breslow NE, Day NE. Statistical methods in cancer research. Vol 1. The analysis of case-control studies. IARC Scientific Publication 32 Lyon, 1980.

15 Republic of South Africa. Department of Health. National Health Information System. Evaluation of the new Death Notification form B1663, Pretoria, 2001 http://www.doh.gov.za/nhis/index.html [Accessed 6 Nov 2003].

16 Mzileni O, Sitas F, Steyn K, et al. Lung cancer, tobacco and environmental factors in the African population of the Northern Province, South Africa. Tobacco Control 1999;8:398-401.

17 Pacella-Norman R, Urban MI, Sitas F, et al. Risk factors for oesophageal, lung, oral and laryngeal cancers in black South Africans. Br J Cancer 2002;86:1751-6.

18 Centers for Disease Control. Smoking attributable mortality - Mexico, 1992. MMWR Morb Mortal Wkly Rep 1995;44:372-81.

19 Ezzati M, Lopez AD. Measuring the accumulated hazards of smoking: global and regional estimates for 2000. Tobacco Control 2003;12:79-85. 